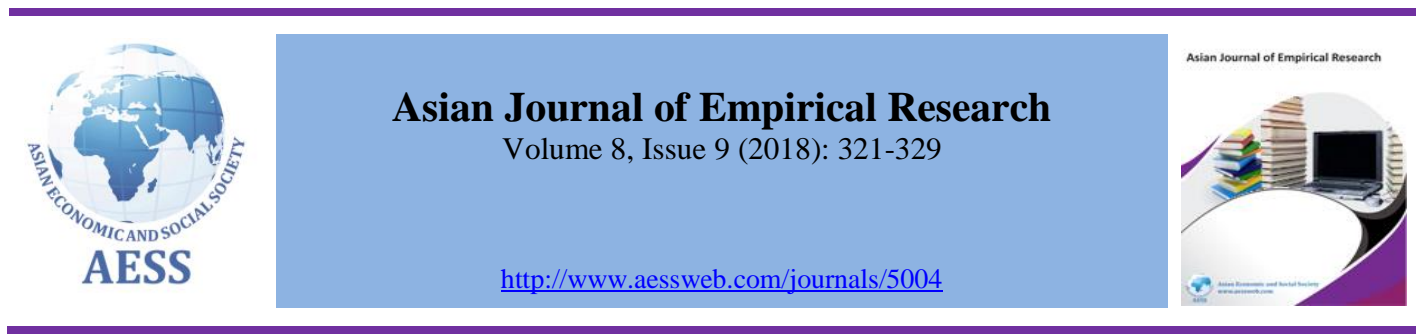

\title{
An empirical study on reverse psychology applied in advertising messages
}

\section{Winslet Ting Yan Chan i \\ Chi Hong Leung}

Department of Management and Marketing, The Hong Kong

Polytechnic University, Hong Kong, The People's Republic of China

\winslet.ty.chan@polyu.edu.hk Corresponding author

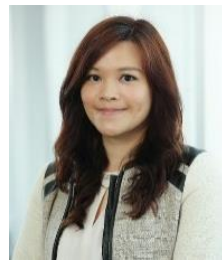

(Corresponding author)

\section{ARTICLE HISTORY:}

Received: 08-Sep-2018

Accepted: 08-Oct-2018

Online available: 25 -Oct-2018

\section{Keywords:}

Reverse psychology marketing, Psychological reactance,

Advertising messages,

Consumer attitudes

\begin{abstract}
Reverse psychology, also known as psychological reactance, is a social influence tactic that encourages people to act the opposite of what it is suggested. This technique has been applied by marketers in advertising in which a negative message or tagline (e.g., "you don't buy the product) is used to motivate consumers to make purchase. Psychological reactance theory advocates that reactance occurs when people react to restore a freedom when it is eliminated or threatened to be eliminated. The expected response to an advertising message of not doing something is to do it. An experiment was designed to measure if 52 subjects were comfortable with negative advertising messages yet felt interested in them. Results showed that $49.7 \%$ of subjects were interested in these messages, although $76.6 \%$ of them were uncomfortable with the negative advertising messages. Results suggested that the application of reverse psychology tactic in advertising enable marketers to create awareness and raise interest of consumers. It is also interesting to find out that $40.8 \%$ of subjects were uncomfortable with the messages but showed interest in them. The practical way of using reverse psychology in advertising is discussed at the end of paper with an example for illustration.
\end{abstract}

\section{Contribution/ Originality}

By conducting the experiment to test reverse psychology of consumers, this study showed that consumers are interested in advertising framed with negative message, although they are uncomfortable with the negative messages. Managerial implications on using reverse psychology in advertising to raise customers' awareness and interest with real-life examples are included in this study.

DOI: 10.18488/journal.1007/2018.8.9/1007.9.321.329

ISSN (P): 2306-983X, ISSN (E): 2224-4425

CrossMark

How to cite: Winslet Ting Yan Chan and Chi Hong Leung (2018). An empirical study on reverse psychology applied in advertising messages. Asian Journal of Empirical Research, 8(9), 321-329.

(C) 2018 Asian Economic and Social Society. All rights reserved 


\section{INTRODUCTION}

Psychological reactance is a motivational state of arousal after a freedom has been eliminated or threatened to be eliminated (Brehm, 1966). People are free to select what they like (Clee and Wicklund, 1980) but when the freedom is limited, reactance can be provoked. Reactance arouses when there is an intention to reduce freedom, it puts emphasis on the motivational and affective sides of resistance (Knowles and Linn, 2004), and it motivates ones to reestablish their lost or threatened freedoms (Eagly and Chaiken, 1993). Reactance will become more intense when the number of jeopardized behaviours is more, the degree of the threat is higher and the importance of the eliminated freedom is greater (Brehm et al., 1966). Researchers focused on choice situations and measured reactance in terms of choice reversals when unavailable options were more attractive. Reactance theory is applied in various contexts. For example, the persuasive messages in public service announcements have applied reactance theory to affect consumers to behave in a desired way. The reduction in freedom of choice makes the unavailable options more desirable. For instance, an experiment (Lessne and Notarantonio, 1988) proved that constraining the choices of participants will increase the attractiveness of the products, when there was a wide variety of were available for participants to choose or purchase. Reactance also produces counter-intuitive results. For example, when experts' recommendations are not in favour of a dominant option or against to majority, consumer satisfaction levels decreases (Fitzsimons and Lehmann, 2004). Reactant responses also affect ethical consumer behaviours. Scarcity affects the degree to which ones are willing to purchase pirated products and this willingness increases with unavailability (Miyazaki et al., 2009). Reactance research was performed in the context of advertising (White et al., 2008). For instance, justification and utility of emails have to be designed cautiously to improve their communication effectiveness. Consumers measure the trade-offs between the amount of personal information in emails and the utility and justification of emails. There are antecedents and consequences of the perception of popup advertisement intrusiveness (Edwards et al., 2002). Although limitation of freedom arouses reactance, there are other factors minimizing it like entertaining and informative ads.

The consequence of psychology reactance is restoration of freedom (Worchel and Brehm, 1971). In direct restoration, the individuals carry out it themselves. In indirect restoration, on the contrary, the sense of autonomy is reinstated by a third party. There are both mental and behavioral effects of freedom restoration. The former changes in judgment or perception, while the latter attempts at freedom restoration observable by others. The boomerang effect is the most extreme behavioral response to threatened freedom. The individuals increase their liking of the threatened position and may engage in the prohibited activity. In the context of persuasive communications, the direct and mental restoration are the most common because they do not rely on third parties and usually available at once when facing restriction on freedom. The aim of persuasive communications is assumed to impact behavior ultimately and being receptive to the message is the first step of the impact. To achieve behavioral goals requires affective changes that are related to emotions and attitudes, and cognitive changes that are related to learning. However, when receptivity to message is low, the path is blocked for such changes to take place (Krugman et al., 1999).

Reverse psychology involves the advocacy of a belief or behavior that is opposite to the desired one and expects that this will encourage ones to do what is desired actually. This approach relies on psychological reactance in which the individual reacts negatively and choose the option that is advocated against. Usually, individuals are not aware of this approach. A typical application of reverse psychology in advertising is "Don't buy this jacket" from Patagonia (see Figure 1). This advertising campaign aims to tell consumers that the company cares more about consumerism and the environmental strains, while encouraging consumers should not buy more than what they need. This actually creates a sense of alliance that makes consumers buy the jacket. In the Action-Interest-DesireAction (AIDA) model of marketing communication, the first two stages are awareness and interest in which advertising is usually used to draw attention of consumers and create awareness of a product followed by feeling interested in it. To apply reverse psychology, an advertising message will be opposite to what is desired and may make people feel uncomfortable and dislike the message. Curiosity 
may be the reason why reverse psychology works in marketing. Consumers like to learn more about strange advertising messages such as "Don't buy this jacket". However, this approach seems risky for marketers.

Individual experience reactance occurs when one's freedom to behave is threatened. The response can strengthen desire to the threatened freedom mentally or physically. Individual responses to such a threat can be influenced by factors like reward compensating for the loss of freedom (Wendlandt and Schrader, 2007). In consumer marketing, there are various reactance theory applications (Clee and Wicklund, 1980). The major study theme is reactance against promotional effect like online promotion (Edwards et al., 2002) and personal selling (Wicklund et al., 1970). Hard selling is a typical example demonstrating reactance effects. Subjects show a less favorable attitude to the promoted product. When individuals evaluate advertising and finds it intrusive, they may feel that advertising prevents them from accessing information and capability of processing information that displeases their feeling caused by different types of advertising stimuli. There are several factors triggering perceived advertising irritation including perceived loss of ones' behavior control, advertising intrusiveness, and advertised products (Li et al., 2002; Morimoto and Chang, 2006).

The aim of this paper is to find out whether reverse psychology in advertising makes consumers interested in a message although they may feel uncomfortable with the message initially. The paper will first review how reverse psychology has been applied in advertising. Then, the research method used to measure respondents' feeling about a message and their interest will be suggested. Finally, the experimental results and marketing insights will be discussed.

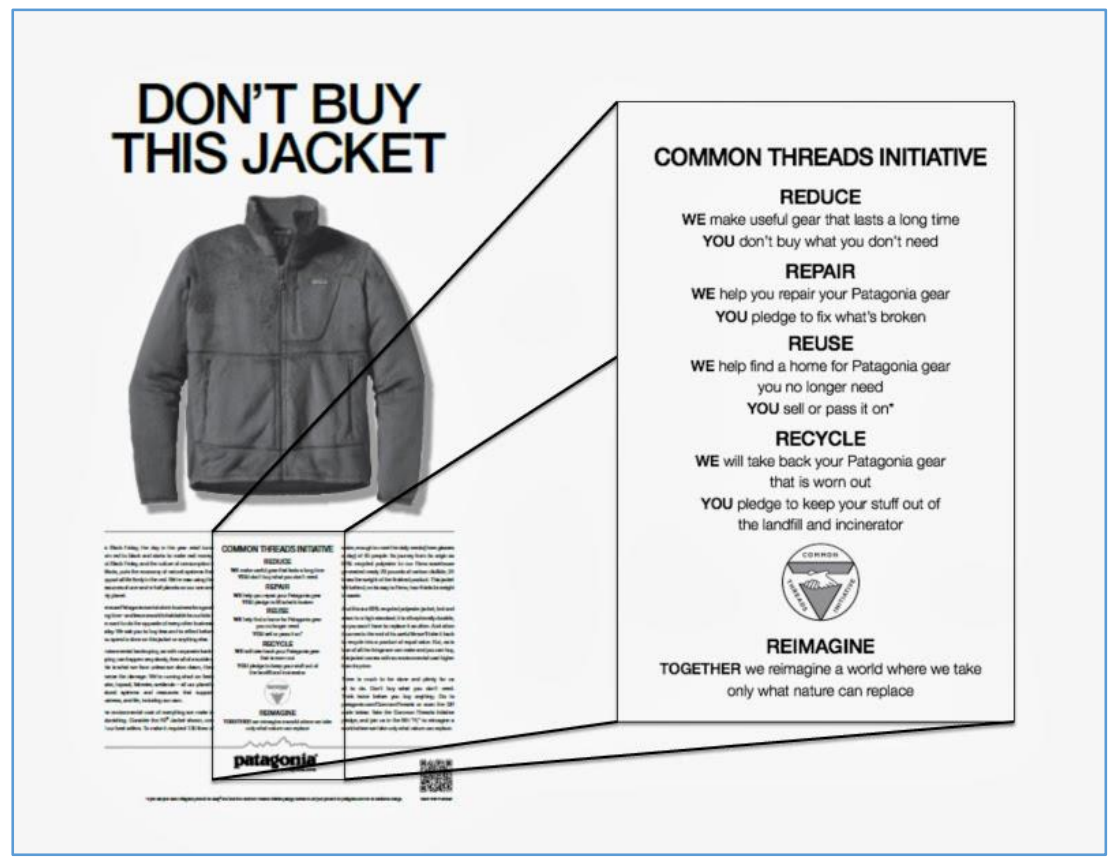

Figure 1: Advertising of "Don't buy this jacket" (Source: http://reversedads.blogspot.hk)

\section{REVERSE PSYCHOLOGY IN ADVERTISING}

Reverse psychology is applied when the intent of an action is the opposite of what is done or stated (MacDonald et al., 2011). Usually, people are psychologically willful to react to stimuli by ignoring or contradicting it. Little research has been performed to evaluate the effectiveness of reverse psychology on the consumer decision process. Reverse psychology is used in a paradoxical manner from the theoretical perspective (Sinha and Foscht, 2016) and it features reactance and contrast that are well established concepts in psychology (Brehm, 1966; Brehm, 1989). Reactance is a motivational 
reaction to the threatened or restricted behavioral freedom while contrasting messages may lead to one's interest and further exploration of the message.

There are some marketing concepts related to reverse psychology marketing. The first one is demarketing that refers to discourage and diminish demand. De-marketing is usually used in decreasing unhealthy habits like cigarette and battling supply shortages. The second one is anti-marketing that refers to anti-advertising ideology and anti-consumption. For example, many anti-marketing brands have their retailer stores in inconvenient locations or the stores open in inconvenient time and this creates contrast between other typical brands leading to differentiation. The third one is paradoxical marketing that refers to combination of contradictory factors to create a win-win situation for both consumers and the firm (Driscoll, 2008). Paradox is a phenomenon when two apparently opposite factors like globalization and localization are found simultaneously (Poole and Van del Ven, 1989). Reverse psychology marketing is with the characteristics of these concepts mentioned above. Thus, application of reverse psychology marketing may include launching products during the off season, decreasing advertising intensity, understocking inventory, offering restricted or limited services, ignoring useful product attributes, or choosing inconvenient store locations (Miklos-Thal and Zhang, 2013).

Conventionally, an advertising message portrays a brand and shows only the good features while the contrast of the reverse psychology marketing strategy surprises consumers with its unexpected advertising stimuli and they are told to respond in an unrespecting way (Sinha and Foscht, 2016) like "Don't trust advertising" in the marketing campaign of BMW in 2007 (Krix, 2007). Consumers are interested in searching for more information because of this paradoxical tagline. This advertising tactic involves great cognitive processing since the time spent on the advertising is longer (Sinha and Foscht, 2016). In addition, missing or vague information in advertising seems to be opposite of the traditional marketing tactic. Customers will like to find out more information about the brand when there is no product attribute cue (Mayzlin and Shin, 2011). It is suggested that when the company is sure that information searched by the consumers is positive, it may withdraw from advertising its products with positive attributes.

One of the major challenges for reverse psychology marketing is that it is still in its experimental manner. Marketers are concerned about the implementation of a marketing tactic not based on conventional ideas. In addition, marketers are not certain of the consumers' reaction to their goods. Conducting marketing research before launching an advertising campaign is useful for marketers to understand if a particular advertising message is acceptable for the market. However, reverse psychology techniques usually use strange messages that may make consumers feel unpleasant and uncomfortable. In a typical marketing survey, such advertising messages trigger a longer cognitive process in which respondents may attempt to respond in a logical manner. They may not state that they are interested in advertising that may make them feel uncomfortable. Thus, the collected data in the survey may not really reflect the consumers' attitudes to the reverse psychology application in an advertising campaign. In the study of this paper, an experiment was carefully designed to collect consumers' attitudes to advertising messages to find out if these messages were practical to be used to create awareness and raise consumers' interest.

\section{RESEARCH METHOD}

There are two thinking systems of a human brain: System 1 and System 2 (Kahneman, 2011). The former is a fast automatic and usually unconscious way of thinking. It is efficient but prone to errors and biases. The latter is slow and controlled way of thinking. Although it is effortful, it often leads to correct decisions (Chan and Leung, 2018).

To measure brand awareness of a product, the recommended route should be with System 1. When research data indicate that a particular advertising message compels buyers to purchase an item, the data is only accurate if they really purchase the item. This decision on whether to buy the product is 
possibly conjured up promptly in an intuitive thinking process and, thus, the only precise way to evaluate this intuitive nature is through System 1. In a traditional survey, respondents may ponder their answers for a while and stray into System 2 that is not suitable for such a decision. It is necessary to capture their unabashed feelings towards advertising messages and brands and avoid any risk of stopping to think carefully about their attitudes and feelings.

A more complex research collection process may make respondents to think with System 2 and collected data will be generated by this system. For example, simply decreasing the legibility of the font used in a test can make respondents more likely to change to think with System 2 (Frederick, 2005). Therefore, when respondents are asked to express how they feel about an advertising message and then if they are interested in the same message, it is probably that they may switch to think with System 2 and the collected data cannot reflect their accurate feelings and attitudes to the brand. It is logically assumed that in a survey when a respondent states that he feels negatively about a message like "Don't buy this jacket", he may also states that he is not interested in the same message. It is because the respondent is processing the same message mentally long enough to switch to System 2 to make his two replies consistent with each other.

One simple way to this problem is to collect data on their feelings and interests separately. In the first survey, a respondent states whether he feels comfortable with a negative advertising message like "Don't buy this jacket". After a week or longer, in the second survey, the respondent is asked to select one of the two opposite messages like "Buy our product" and "Don't buy this jacket" in the advertising context that is more interesting for him (see Figure 2).

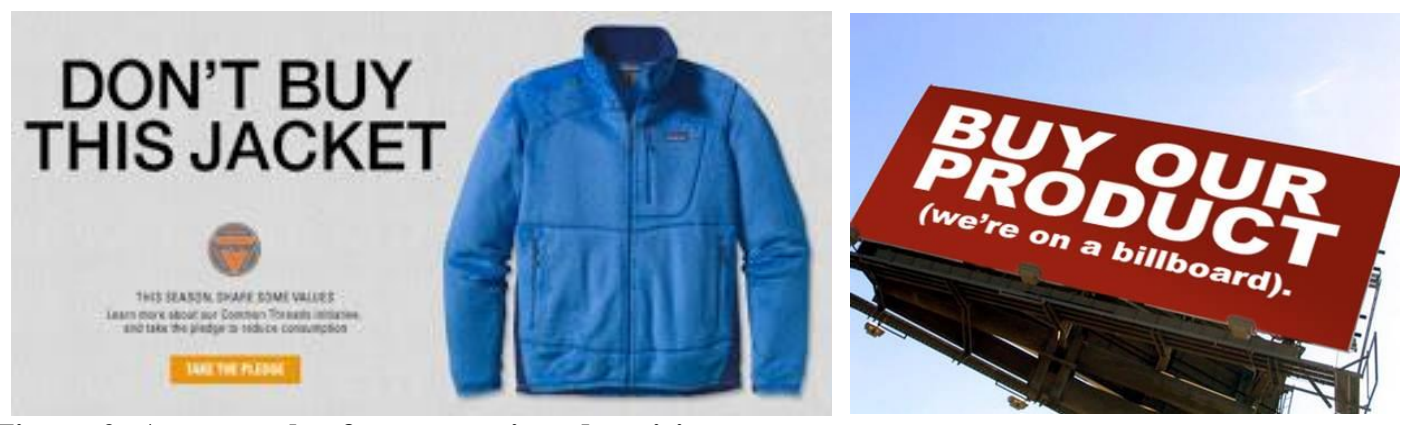

Figure 2: An example of two opposite advertising messages

Table 1 shows the ten advertising messages studied in the experiment. The respondents were asked to express if they felt comfortable and interested in them in two separate surveys at different times.

Table 1: Ten advertising messages studied in the experiment

1. Don't buy this jacket

2. Text and drive

3. You're not ready

4. It's probably not for you

5. No one will read this poster

6. It is not useful for you

7. It never arouses your interest

8. You do not know how to use it

9. You are not smart to select it

10. You never regret not buy it

In the first survey, for each message in Table 1, a respondent might select three options: "feel comfortable", "neutral" and "feel uncomfortable". If the respondent selected "neutral", this message would not be processed again in the second survey. Only when either "feel comfortable" or "feel uncomfortable" was selected, the corresponding pair of opposite messages (like ones in Figure 2) will 
be presented in the second survey in which the respondent selected either "feel interested" or "feel uninterested". The purpose of this experimental design was to find out the following four types of attitudes to the messages.

\begin{tabular}{lcc}
\hline & Feel interested & Feel uninterested \\
\hline Feel comfortable & Type 1 & Type 3 \\
Feel uncomfortable & Type 2 & c \\
\hline
\end{tabular}

Type 1 and Type 4 are consistent because respondents state their attitudes in the same manner (either positively or negatively) in two surveys. Type 2 and Type 3 are contradictory because respondents states their attitudes to the same message positively in the first survey but negatively in the second survey, or vice versa. These two types are especially important in this study because their proportions directly reflect whether respondents really have opposite attitudes to reverse psychology advertising. A high proportion of Type 2 can show the effectiveness of reverse psychology advertising because although a negative message looks strange, it can really create awareness and make consumers interested in it.

\section{EXPERIMENTAL RESULT}

In this experiment, there were 52 subjects who were university students studying business subjects. In the first survey, they were asked to state if they felt comfortable with the advertising messages in Table 1. There were $520(52 \times 10)$ responses collected in this survey and 380 of these messages were nonneutral (i.e., either feeling comfortable or feeling uncomfortable).

These 52 subjects participated in the second survey that was performed one week after the first one. Each subject only processed the messages that were non-neutral to him/her as stated in the first survey. For each non-neutral message, subjects were given a pair of advertising in which one applied reverse marketing while another did not (like those in Figure 2). Subjects were asked to select the one that interested them. The results were presented in Table 2.

Table 2: Experimental results of the second survey

\begin{tabular}{lccc}
\hline & Feel interested & Feel uninterested & Total \\
\hline Feel comfortable & $34(8.9 \%)$ & $55(14.5 \%)$ & $89(23.4 \%)$ \\
Feel uncomfortable & $155(40.8 \%)$ & $136(35.8 \%)$ & $291(76.6 \%)$ \\
Total & $189(49.7 \%)$ & $191(50.3 \%)$ & $380(100.0 \%)$ \\
\hline
\end{tabular}

The experimental results showed that the majority (76.6\%) of respondents felt uncomfortable with the negative messages (like "You don't buy this jacket"). However, among these respondents, more than the half $(40.8 \%>35.8 \%)$ was interested in the negative messages actually. This experiment proved that when an advertising message is strange and may even create a negative feeling to the audiences, they are interested in the message and like to learn more about it. This experimental design was able to measure these two attitudes separately, instead of their measurements being affected by each other in the traditional survey design.

The experimental results also revealed that about half the respondents $(49.7 \%)$ were interested in the negative messages, no matter they felt comfortable with the messages or not. Thus, reverse psychology could achieve the aim of advertising to create awareness and raise the interest (i.e., the first two elements of the AIDA model), compared with the traditional marketing communication.

\section{CONCLUSION}

Reverse psychology is a new promising approach for a brand to differentiate itself from others. Its application in advertising can draw attention of the audiences who would like to learn more about an 
unusual message. It can raise consumers' interest in a way different from what traditional marketing can achieve. Traditional marketing attempts to find what consumers want and fulfill their requirements while reverse psychology pays more attention to what the firm think is suitable for their major customers (Sinha and Foscht, 2007). Using reverse psychology, firms can send refreshing messages contrary to push marketing that puts emphasis on loud and attention seeking. Consumers may consider messages restricting freedom in greater detail. Information receptivity is the important initial step without which changes in attitudes and behaviors are impossible to occur.

The experiment in this study proved that there were certain proportion of audience feeling interested in reverse psychology applied in advertising messages although they might express negative feelings at the same time. The cautious design of the experiment was proved to be able to capture such inconsistent attitudes of the subjects. This kind of experiments should be conducted by a firm to confirm if their messages are really practical and acceptable before it launches a corresponding reverse psychology marketing campaign in the market.

Reverse psychology marketing is a risky strategy for most companies. To apply this strategy successfully, there are several conditions to be met. First, customers should be understood and reverse psychology is able to resonate with customers so that they intrigued enough to request for further information about the product, instead of getting uninterested in the product. Second, there should be positive associations that exceed the negative perception of the product. The negative message should not be only thing connecting to the product. Positive associations may be related to, for example, brand strength, shared values and customer experiences. Third, there should be the follow up strategy that ensures all the requested information helps customers to make the right buying decision. For example, the official websites, search engine optimization and social media can be used to spread the relevant information to customers who are interested in the product. The follow up strategies should be strong enough to intrigue and delight to highlight benefits of the product.

The marketing campaign in Figure 1 is a typical example illustrating how to meet these conditions to apply reverse psychology marketing. First, the image in advertising creates a positive impression. The negative message creates a sense of exclusivity and a barrier to reinforce such desire. Customers want the product although they are told not to buy it. In addition, advertising provides right information to explain the brand values. The company can create positive associations and people feel like that they are making the right decision. Customers are potentially turned into advocates for the product. Moreover, the potential customers may seek out more information from various sources like peers on social media and information on the official websites and they are not likely to run into a negative opinion.

The current study mainly focused on the advertising context. It would be of interest to study issues more scientifically with respect to communication medium, message topic, expected responses toward advertising and the degree of threat to freedom. Consumer may learn to block out threats to freedom when there is repeated exposure. From the marketing perspective, it is necessary to find out the most suitable way of applying reverse psychology in marketing practices.

\footnotetext{
Funding: This study received no specific financial support.

Competing Interests: The authors declared that they have no conflict of interests.

Contributors/Acknowledgement: All authors participated equally in designing and estimation of current research.

Views and opinions expressed in this study are the views and opinions of the authors, Asian Journal of Empirical Research shall not be responsible or answerable for any loss, damage or liability etc. caused in relation to/arising out of the use of the content.
} 


\section{References}

Brehm, J. W. (1966). A theory of psychological reactance. New York: Academic Press Inc. view at Google scholar

Brehm, J. W. (1989). Psychological reactance: Theory and applications. Advances in Consumer Research, 16(1), 72-75. view at Google scholar

Brehm, J. W., Stires, L. K., Sensenig, J., \& Shaban, J. (1966). The attractiveness of an eliminated choice alternative. Journal of Experimental Social Psychology, 2(3), 301-313. view at Google scholar / view at publisher

Chan, W. T. Y., \& Leung, C. (2018). A preliminary study on dual process thinking in marketing education. Asian Journal of Empirical Research, 8(5), 186-194. view at Google scholar / view at publisher

Clee, M., \& Wicklund, R. (1980). Consumer behavior and psychological reactance. Journal of Consumer Research, 6(4), 389-405. view at Google scholar / view at publisher

Driscoll, A. O. (2008). Exploring paradox in marketing: Managing ambiguity towards synthesis. Journal of Business and Industrial Marketing, 23(2), 95-104. view at Google scholar / view at publisher

Eagly, A. H., \& Shelly, C. (1993). The psychology of attitudes. New York: Harcourt Brace. view at Google scholar

Edwards, S. M., Li, H., \& Lee, J. (2002). Forced exposure and psychological reactance: Antecedents and consequences of the perceived intrusiveness of pop-up ads. Journal of Advertising, 31(3), 83-95. view at Google scholar / view at publisher

Fitzsimons, G. J., \& Lehmann, D. R. (2004). Reactance to recommendations: when unsolicited advice yields contrary responses. Marketing Science, 23(1), 82-94. view at Google scholar / view at publisher

Frederick, S. (2005). Cognitive reflection and decision making. Journal of Economic Perspectives, 19(4), 25-42. view at Google scholar

Kahneman, D. (2011). Thinking, fast and slow. Macmillan/Allen Lane, London. view at Google scholar

Knowles, E. S., \& Linn, J. A. (2004). The importance of resistance to persuasion. In Resistance and Persuasion, Eric S. Knowles and Jay A. Linn, Eds., 3-10. Mahwah, NJ: Lawrence Erlbaum. view at Google scholar

Krix, P. (2007). BMW tells customers 'Don't trust advertising'. Automotive News Europe, http://europe.autonews.com/article/20070917/ANE/70908025/bmw-tells-customers\%E2\%80\%98don\%E2\%80\%99t-trust-advertising\%E2\%80\%99, retrieved 11 December 2017.

Krugman, D. M., Fox, R. J., \& Fischer, P. M. (1999). Do cigarette warnings warn? Understanding what it will take to develop more effective warnings. Journal of Health Communication, 4(2), 95-104. view at Google scholar / view at publisher

Lessne, G. J., \& Notarantonio, E. (1988). The effects of limits in retail advertisements: a reactance theory perspective. Psychology and Marketing, 5(1), 34-44. view at Google scholar / view at publisher

Li, H., Edwards, S. M., \& Lee, J. H. (2002). Measuring the intrusiveness of advertisements: Scale development and validation. Journal of Advertising, 31(2), 37-47. view at Google scholar / view at publisher

MacDonald, G., Nail, P. R., \& Harper, R. (2011). Do people use reverse psychology? An exploration of strategic self-anticonformity, Social Influence, 6(1), 1-14. view at Google scholar / view at publisher

Mayzlin, D., \& Shin, J. (2011). Uninformative advertising as an invitation to search. Marketing Science, 30(4), 666-685. view at Google scholar / view at publisher

Miklos-Thal, J., \& Zhang, J. (2013). (De) marketing to manage consumer quality inferences. Journal of Marketing Research, 50(1), 55-69. view at Google scholar / view at publisher

Miyazaki, A. D., Rodriguez, A. A., \& Langenderfer, J. (2009). Price, scarcity, and consumer Willingness to purchase pirated media products. Journal of Public Policy \& Marketing, 28(1), 71-84. view at Google scholar / view at publisher 
Morimoto, M., \& Chang, S. (2006). Consumers' attitudes toward unsolicited commercial e-mail and postal direct mail marketing methods. Journal of Interactive Advertising, 7(1), 1-11. view at Google scholar / view at publisher

Poole, S. M., \& Van de Ven, A. H. (1989). Using paradox to build management and organization theories. Academy of Management, 14(4), 562-778. view at Google scholar / view at publisher

Sinha, J. I., \& Foscht, T. (2007). Reverse psychology marketing: The death of traditional marketing and the rise of the new "pull" game. Palgrave Macmillan Publishers Limited, Palgrave Macmillan, London. view at Google scholar / view at publisher

Sinha, J. I., \& Foscht, T. (2016). Reverse psychology tactics in contemporary marketing. The Marketing Review, 16(3), 343-353. view at Google scholar / view at publisher

Wendlandt, M., \& Schrader, U. (2007). Consumer reactance against loyalty programs. Journal of Consumer Marketing, 24(5), 293-304. view at Google scholar / view at publisher

White, T. B., Zahay, D. L., Thorbjornsen, H., \& Shavitt, S. (2008). Getting too personal: Reactance to highly personalized email solicitations. Market Letter, 19, 39-50. view at Google scholar / view at publisher

Wicklund, R., Slattum, V., \& Solomon, E. (1970). Effect of implied pressure toward commitment on ratings of choice. Journal of Experimental Social Psychology, 6(4), 449-457. view at Google scholar / view at publisher

Worchel, S., \& Brehm, J. W. (1971). Direct and implied social restoration of freedom. Journal of Personality and Social Psychology, 18(3), 294-304. view at Google scholar / view at publisher 